\title{
Vivendo na terra do meio: o mito apurinã revelando a realidade histórica
}

Rogério Sávio Link $k^{*}$

${ }^{1}$ Universidade Federal de Rondônia, Porto Velho/RO - Brasil

\section{RESUMO}

Este artigo tem como objetivo evidenciar a materialidade histórica vivida pelo povo Apurinã a partir de sua cosmologia; ou seja, se a cosmologia presente em suas narrativas míticas registra aspectos da historicidade apurinã. A hipótese do artigo é que a cosmovisão apurinã que os situa como um "povo do meio" tem sua origem na imanência histórica e, como tal, sofreu mudanças na longa duração. Transformando-se em transcendência teológica, a narrativa preservou traços da historicidade que podem ajudar a interpretar a história do povo Apurinã e a história regional. $\mathrm{O}$ artigo está construído a partir de uma discussão bibliográfica específica, mas também utiliza fontes históricas dos primeiros contatos e se baseia em observaçôes de campo.

Palavras-chave: Apurinã; cosmovisão; memória; Rio Purus.

\section{Living in the middle land: the Apurinã myth revealing historical reality}

\section{ABSTRACT}

This article aims to show the historical materiality experienced by the Apurinã people based on their cosmology. It asks, does the cosmology present in the group's mythical narratives register aspects of the Apurina historicity? The article's hypothesis is that the Apurinã worldview, which places Apurinã as a "middle people," has its origin in historical immanence, and, as such, has experienced changes over time. Transforming into theological transcendence, this worldview has preserved traces of historicity that may help us to interpret the history of both the Apurinã people and the region they live in. The article is based on a specific bibliographic discussion and also uses primary sources and field observations.

Keywords: Apurinã; worldview; memory; Purus River.

DOI: http://dx.doi.org/10.1590/2237-101X02204612

Artigo recebido em 14 de novembro de 2019 e aceito para publicação em 26 de junho de 2020.

* Professor da Universidade Federal de Rondônia / Departamento de História, Porto Velho/RO - Brasil. E-mail: linkrogerio@yahoo.com.br. ORCID: https://orcid.org/0000-0002-0956-3227. 


\section{Viviendo en la tierra del medio: el mito de Apuriná revelando la realidad histórica}

\section{RESUMEN}

Este artículo tiene como objetivo evidenciar la materialidad histórica vivida por el pueblo Apurinã a partir de su cosmología; o sea, sí la cosmología presente en sus narrativas míticas registra aspectos de la historicidad apurinã. La hipótesis del artículo es que la cosmovisión apurinã que los localiza como un "pueblo del medio" tiene su origen en la inmanencia histórica y, como tal, sufrió transformaciones en la larga duración. Transformándose en transcendencia teológica, la narrativa preservó trazos de la historicidad que pueden ayudar a interpretar la historia del pueblo Apurinã y la historia regional. El artículo está construido a partir de una discusión bibliográfica específica, pero también utiliza fuentes históricas de los primeros contactos y se basa en observaciones de campo.

Palabras clave: Apurinã; cosmovisión; memoria; Río Purus.

\section{Introdução}

Como parte de uma tese de doutoramento em História Indígena defendida em 2016, este artigo busca evidenciar a materialidade histórica vivida pelo povo Apurinã a partir de sua cosmologia; ou seja, se a cosmologia presente em suas narrativas míticas registra aspectos da historicidade apurinã. A questão fundamental para a historiografia é se as narrativas míticas podem ser tomadas como fontes para interpretaçôes científicas. É verdade que o mito não pode ser considerado História desde o ponto de vista acadêmico e científico. Normalmente associado à noção de falsidade, de senso comum e ou como sinônimo de mentira, o substantivo mito também possui uma longa tradição nos trabalhos historiográficos. Os historiadores inclusive pensavam que sua grande tarefa era demonstrar que muito daquilo que as pessoas pensavam ou diziam do passado era mito, isto é, não correspondia à veracidade histórica. A História, nesse sentido, seria um antídoto contra o pensamento mítico (WHITE, 2001 [1978], p. 99, 140). No entanto, para uma pesquisa que se insere no campo da história indígena, há a necessidade implícita de abordar o mito como uma forma narrativa que preserva a memória. Nesse sentido, os trabalhos de Lévi-Strauss (2010 [1964]) e Marshall Sahlins (1997 [1987], 2008 [1981]) propiciaram um novo olhar sobre a realidade mítica. É da antropologia, portanto, que sai o impulso para essa guinada interpretativa. A obra de Sahlins, entretanto, parece ter mais relevância para a historiografia, pois sua teoria da história influenciou os novos historiadores preocupados em fugir de interpretaçóes dicotômicas e, sobretudo, em desvelar a agência indígena nos processos históricos. 
Embora a narrativa mítica não esteja pautada pela preocupação cronológica, nem pela intenção de preservar a memória do desenrolar de um acontecimento - pois é caracterizada por um enredo metafísico, o que a distancia ainda mais da preocupação, por vezes, mais materialista da história -, ela descreve significados que podem desvelar estruturas de pensamento (cosmovisão) e, portanto, de forma de ação no mundo (ética) que permite observar as continuidades e as descontinuidades que estariam presentes na memória mítica de um povo. Para a cultura ocidental que demarca o universo científico, o mito é uma interpretação da história e a História é a interpretação "verdadeira". Já para outras culturas (notadamente as indígenas), o mito pode ser a materialização da história; ou, como diria Marshall Sahlins, a "verdade" histórica está no mito. "Os incidentes da vida e morte de Cook no Havaí foram, em muitos sentidos, metáforas históricas de uma realidade mítica” (SAHLINS, 2008 [1981], p. 34). Assim, os mitos são constantemente revividos, tornados história pelas pessoas ou, como diz Sahlins: "Incidentes míticos constituem situaçôes arquetípicas. As experiências dos protagonistas míticos são reexperiênciadas pelos vivos em circunstâncias análogas. Mais ainda, os vivos se transformam em heróis míticos" (SAHLINS, 2008 [1981], p. 38). Os mitos são, dessa forma, revividos como eventos na longa duração.

Sahlins também vai demonstrar como as ações históricas são modeladas pelo simbólico como no caso da luta entre os ingleses e os Maori entre 1844 e 1846. A revolta teria surgido por causa do mastro da bandeira. Os Maori identificaram o mastro da bandeira erguido pelos ingleses com aquele que eles erigiam como lugar sagrado e, portanto, símbolo de domínio. Os relatos ingleses consideram a revolta dos Maori como indício de inferioridade, pois, em vez de lutar pelo controle político e econômico, lutavam para derrubar um mastro. Sahlins, no entanto, em sua abordagem, demonstra como também os ingleses estavam motivados simbolicamente, pois lutavam por uma bandeira que consideravam sagrada, embora tentassem ocultar isso de si mesmos. Houve aí uma confluência de simbologias que representava a posse e o domínio efetivo das terras (SAHLINS, 1997 [1987], p. 84-93).

Assim como Sahlins, Alan Passes (2002, p. 183) também trabalhou com narrativas míticas de um grupo Aruak, os Palikur, para observar as representaçôes do passado. Para ele, o mito é, como na história, uma forma cultural de conhecimento social. Esse conhecimento é alcançado através de uma permanente reprodução, reformulação e reinterpretação da memória, da tradição e das narrativas. "Assim o mito parece ser uma ferramenta intrinsecamente humana para processar experiência histórica e seus aspectos traumáticos, os quais no contexto Ameríndio desde a Conquista mormente implica as açôes dos brancos" (PASSES, 2002, p. 189-190)1. O mito é, pois, uma construção social sempre atualizada. Dessa forma é que Jonathan D. Hill (2002, p. 242), também estudando um grupo Aruak da Venezuela, os Wakuénai, chega à conclusão de que eles preservariam na memória do grupo a chegada dos europeus.

\footnotetext{
${ }^{1}$ Tradução própria. No original: "Myth thus seems to be an intrinsic human tool for processing historical experience and its traumatic aspects, which in the Amerindian context since the Conquest mostly implies the actions of whites".
} 
Dessa forma, lanço aqui a proposiçáo de que o povo Apurinã, sobretudo, da região de Boca do Acre e Pauini, considera-se como "um povo do meio", ou seja, as condiçôes materiais de existência engendraram e moldaram uma teologia/cosmologia apurinã da terra morredoura entre duas terras de fartura e perfeição. Minha argumentação baseia-se principalmente no trabalho de Juliana Schiel (2004, p. 242), mas também se inspira na pesquisa de Alan Passes $(2002$, p. 173, 192) que trabalha com a noção de que etnologicamente os Palikur se considerariam como "povo do meio", pois geograficamente e historicamente teriam vivido em uma regiâo de mediaçáo, entre o Brasil e a Guiana Francesa. Passes também trabalha com a noção de etnogênese, pois, para ele, vários povos teriam convergido em uma federaçáo durante o período colonial para se tornarem hoje os Palikur. Dessa forma, os Palikur parecem seguir a tendência geral dos Aruak de criar rapidamente novas confederaçôes interétnicas regionais no contexto dos estados coloniais e nacionais (HILL; SANTOS-GRANERO, 2002, p. 17).

Para o desenvolvimento desta pesquisa, além das fontes bibliográficas sobre os Apurinã e sobre os Aruak, utilizo fontes históricas dos primeiros contatos registradas em extratos de cartas e relatórios produzidos por missionários anglicanos da South American Missionary Society (SAMS) entre as décadas de 1870 e 1880 e observaçóes de campos decorrentes de minha convivência com os Apurinã do Médio Purus entre agosto de 2008 a agosto de 2010 como assessor de um projeto de revitalização linguística e cultural entre os Apurinã mantido pelo Conselho de Missão entre Povos Indígenas (COMIN) e observações feitas entre janeiro e fevereiro de 2013 durante uma pesquisa de campo.

\section{O território apurinã como terra do meio}

O povo Apurinã, que se autodenomina Kãkyty ou Pupỹkary (LINK, 2016, p. 58-59), faz parte da família linguística Aruak (também Arawak ou Maipure), a mais espalhada da América do Sul e talvez de toda a América (Figura 1). A distribuição dos falantes da família Aruak abrange desde o Sul do Brasil até a Flórida, passando pelas terras subandinas do Peru e da Bolívia até o estuário do Amazonas (HECKENBERGER, 2002, p. 99, 102). Os Aruak são únicos no sentido de eles terem ocupado uma vasta regiáo, abrangendo as ilhas caribenhas, a Flórida e toda a Bacia Amazônia e parte da Bacia Platina. Eles mantiveram relações com as principais famílias linguísticas das terras baixas da América do Sul. As evidências arqueológicas também comprovam que eles mantiveram uma rede de trocas em larga escala com as sociedades da Mesoamérica, do Sudeste dos Estados Unidos e dos Andes (HILL; SANTOS-GRANERO, 2002, p. 12). 
Figura 1: Localização dos principais grupos Aruak e seus vizinhos na época do contato

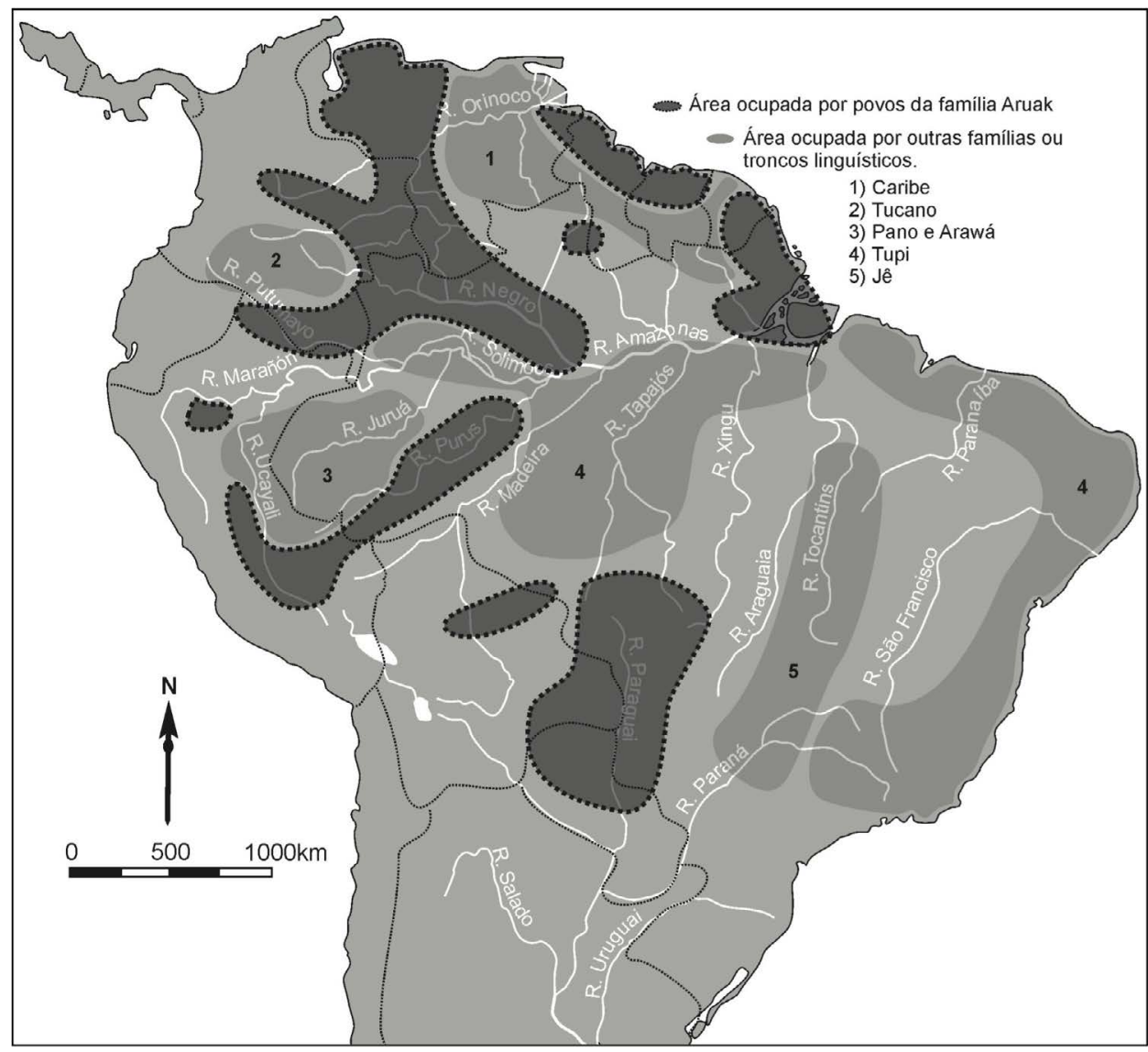

Fonte: Elaborado pelo autor a partir do mapa de Hill e Santos-Granero (2002, p. 2)

Apesar de existirem defensores de que os Aruak teriam se originado na região peruana, devido ao número expressivo de línguas desta família existentes na região, parece haver um acordo entre a maior parte dos etno-historiadores, arqueólogos e linguistas de que a origem dos Aruak encontrar-se-ia na região entre o Rio Solimôes no Brasil e o Médio Rio Orinoco na Venezuela (Figura 2) ao redor de 3.000 a.C. O Rio Negro, portanto, seria o epicentro de dispersão dos Aruak que teriam iniciado um processo migratório entre 1.000 e 500 a.C. A partir dessa região, os Aruak foram ocupando praticamente toda a Bacia Amazônia. Nesse processo, haveria ainda três centros secundários de dispersão: no Rio Orinoco; na confluência do Rio Negro com os rios Solimões, Purus e Madeira; e entre o Alto Madeira e o Alto Purus (HECKENBERGER, 2002, p. 106-107; BRANDÃO; FACUNDES, 2007, p. 119-120). Nesse sentido, os geoglifos do sul da Amazônia brasileira provavelmente são construçóes que testemunham a passagem dos antepassados dos Aruak cujo significado a arqueologia tem interpretado como centros cerimoniais (SCHAAN et al., 2008). 
Figura 2: Local de origem e rotas migratórias dos Aruak

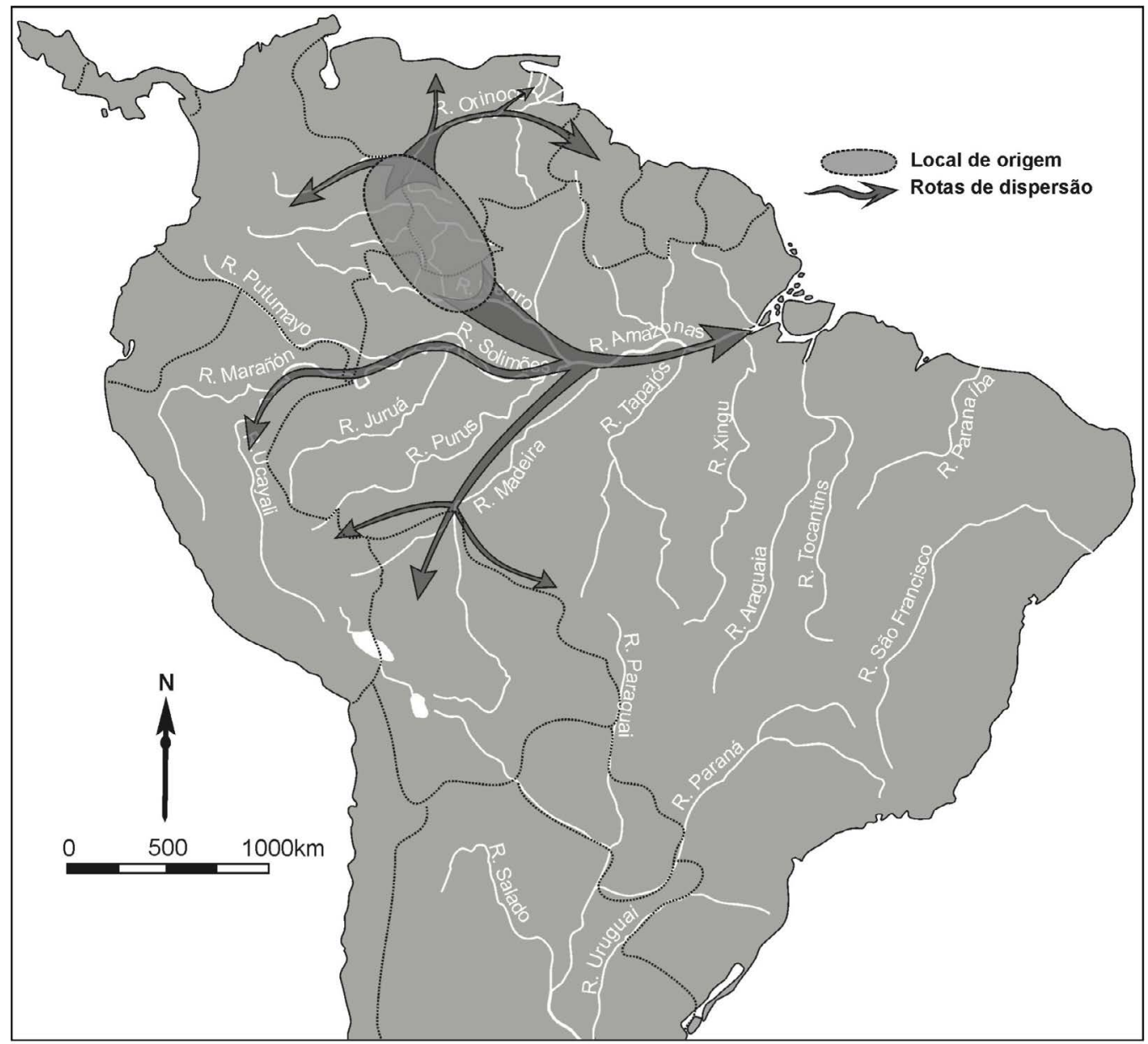

Fonte: Elaborado pelo autor a partir do mapa de Heckenberger (2002, p. 106)

Apesar das evidências arqueológicas e linguísticas apontarem o centro de dispersão dos Aruak como provindo da calha norte da Bacia do Amazonas, as evidências linguísticas a respeito dos Apurinã os ligam mais diretamente aos Aruak dos contrafortes andinos peruanos. Nesse sentido, o linguista Sidney da Silva Facundes (2002, p. 85) situa o povo Apurinã como pertencente ao subgrupo Apurinã-Piro-Iñapari. Isso significa que os ancestrais desse subgrupo teriam se afastado dos demais Aruak dessa região e migrado em direção aos grupos Campa e Pano. O grupo que deu origem aos Piro, aos Apurinã e aos Inápari dividiu-se no sudoeste amazônico, possivelmente próximo à fronteira do Brasil com a Bolívia e com o Peru. O povo Manchineri, como um grupo mais próximo linguisticamente dos Apuriná, poderia, na verdade, ser um subgrupo Piro que teria permanecido mais próximo ao ponto de dispersão ou a ele retornado (BRANDÃO; FACUNDES, 2007, p. 121-122). Os Apurinã, por sua vez, teriam descido o Rio Acre e adentrado no Purus (Figura 3). 
Figura 3: Território tradicional apurinã

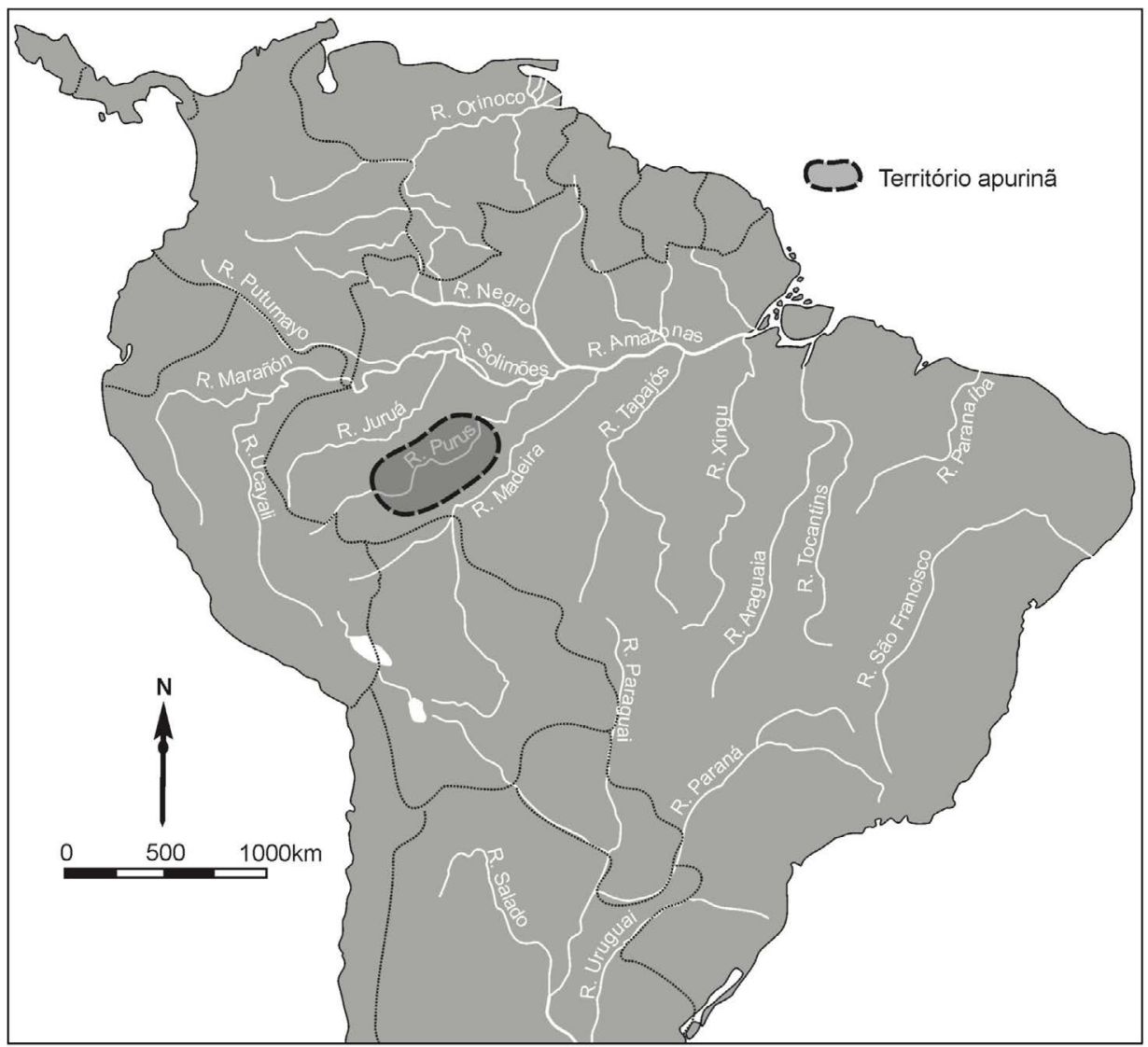

Fonte: Elaborada pelo autor

Assim, a regiáo ocupada tradicionalmente pelos Apuriná, aquela que eles reconhecem como tal, é o Vale do Purus, desde o Acre até a foz do rio, a saber: o Médio e o Baixo Purus e seus afluentes. Esse vale se localiza entre duas bacias, a do Rio Madeira e a do Rio Juruá. Essa situação geográfica por si só já situa os Apurinã num espaço intermediário. No entanto, cosmologicamente, o povo Apurinã também se considera como vivendo na terra do meio. A cosmologia apurinã descreve o território apurinã como uma terra do meio entre as duas terras sagradas Kairiku e Iputuxity. Eles teriam se estabelecido ali depois de uma migraçáo mítica originária. O território atual também é concebido como um espaço transitório; mais do que isso, os Apurinã falam em uma migração ou migraçôes que os levaram até a região ocupada atualmente. De forma que, semelhante aos demais Aruak (HILL \& SANTOS-GRANERO, 2002, p. 19), os Apurinã compartilhariam noçôes de lugares sagrados de origem.

Como narra o mito, as pessoas passariam constantemente de uma terra para outra. A terra que habitualmente ocupam seria apenas um lugar de passagem, entreposto entre Kairiku e Iputuxity, no "meio do mundo" (SCHIEL, 2004, p. 85, 242, 266-267, 442). Schiel não registrou um conceito em apurinã que expressasse essa transitoriedade. Parece que o que ela 
chama de "meio do mundo" é uma tentativa de traduzir a palavra "apanukakutuxu" (apanikakityxi), que significa literalmente "nós continuamos na terra" ( $a=1 \mathrm{pp}$, panika $=$ indicador de continuidade, ityxi $=$ terra). Infelizmente, também náo consegui um termo satisfatório. Uma tentativa poderia ser utilizar o termo ityxiäky (no centro da terra) ou äkytyxi (o centro da terra), mas esses termos não foram verificados no contexto. Outro termo poderia ser Ityximitary (terra grande) que inclusive é o nome dado a uma das terras indígenas do Baixo Purus. Schiel (2004, p. 241) ainda traz o termo "kamaraneruxutu" (kamaranyryxyti = terra do povo cupim), o que ela traduz como "terra de cupim", mas, como veremos adiante, isso já é um resultado da conjuntura do pós-contato.

Conforme narrativas, teria sido em uma migraçáo dessas, acompanhando os Utsamanery (povo que viveria atualmente em Iputuxity), que os Apurinã acabaram ficando na região. Nas histórias míticas, os Apurinã teriam saído de Kairiku em direção à Iputuxity, mas teriam se encantado com a fartura do lugar e foram se acomodando. Os informantes de Schiel (2004, p. 266) dizem que os Apurinã teriam saído de Kairiku, porque lá tinha muita gente e eles queriam procurar terras novas. Assim, essas duas terras são, por vezes, descritas como um espaço geográfico específico ao lado de outras terras. Schiel (2004, p. 56) dá a informação de que Kairiku seria uma "terra na pedra", ou seja, uma terra que se localizaria numa grande pedra ou regiáo de pedra. Realmente, etimologicamente a palavra parece conter o substantivo pedra, pois kaiku seria equivalente ao adjetivo "duro" em português. Schiel também afirma que alguns Apurinã dizem que essa terra se localiza além do Rio Ituxi, já em Rondônia. Seguindo essa mesma linha de que a terra mítica estaria localizada a montante do Rio Purus, alguns informantes da pesquisadora Pirjo Kristiina Virtanen (2016, p. 46) descreveriam Kairiku como uma montanha.

A terra de Iputuxity, por sua vez, estaria situada depois do mar ou longe como até o mar. Para designar o mar, Schiel traz as palavras Putxiwary Wenyte. No entanto, enquanto alguns de seus informantes traduzem como "rio salgado", outros afirmam que putxiwary significa doce, portanto seria mais correto traduzir como "rio doce" (SCHIEL, 2004, p. 241). E de fato parece que a palavra empregada é realmente o adjetivo doce (putxuary) como em putxuamata (beiju doce). Além do mais, a palavra Wenyte guarda relação com Wene (Rio Purus, ou simplesmente rio). Ou seja, enquanto Kairiku remete a uma região de pedra só encontrada em Rondônia ou nos contrafortes andinos, Iputuxity remete aos grandes rios a jusante do Médio Purus.

\section{$\mathrm{O}$ mito e a realidade histórica}

A suspeita, quase que natural, que se pode levantar frente a essa concepção mitológica da terra do meio é a de que ela faria referência a tempos pré-colombianos, nos quais a região 
seria um entreposto comercial que ligaria a região andina ao Baixo Amazonas e também à regiáo caribenha (Orinoco). Os Apurinã viveriam nesse entreposto e/ou seriam mesmo mercadores. Essa afirmação, no entanto, deve ser cautelosa, pois náo se dispóe de pesquisas arqueológicas na região para corroborá-la. Até o término da pesquisa, nenhum dos sítios arqueológicos da regiáo de Boca do Acre e Pauini havia sido escavado. Nenhum sítio arqueológico de Pauini estava sequer registrado no IPHAN (Instituto de Patrimônio Histórico e Artístico Nacional). Consegui localizar apenas uma dissertação em arqueologia defendida por Elaine Wanderley (2013) na qual a autora estuda as apropriaçóes que os Apurinã da Terra Indígena Caititu no município de Lábrea fazem dos sítios e objetos arqueológicos encontrados em sua terra. No entanto, a hipótese não deve ser totalmente descartada com a argumentação de que as sociedades indígenas não teriam capacidade de estabelecer uma rede comercial de longa distância. Os primeiros cronistas da regiáo Amazônica descrevem sociedades com complexos sistemas urbanos, com grande densidade habitacional e com manufaturas superiores às europeias (CARVAJAL, 1941, p. 68; veja também PORRO, 1993, p. 55; e ROOSEVELT, 1992, p. 71-72). Anna Roosevelt (1992, p. 54, 63), por exemplo, a partir de suas pesquisas arqueológicas, vai descrever a regiáo amazônica como um grande centro gerador de migraçôes e de dispersão de cerâmica. Ao contrário do que previram as pesquisas centradas nas terras andinas, a cerâmica teria sido originária do Baixo Amazonas, pois as dataçôes são mais antigas nessa regiâo do que nos Andes, e a partir daí teria se difundido em direção às várzeas pré-andinas e alcançado as terras altas. Sua conclusão a respeito dos cacicados amazônicos é enfática:

A arqueologia pré-histórica antiga e os dados históricos mais recentes revelam a presença destas sociedades complexas, todas ao longo das várzeas dos rios Amazonas e Orinoco e nos contrafortes das costas andinas e caribenhas. Estes extensos domínios abrangeriam dezenas de milhares de quilômetros quadrados, sendo alguns unificados sob chefes supremos. Os cacicados eram belicosos e expansionistas, com uma organização social hierárquica, mantida por tributos e por um modo de subsistência baseada na colheita intensiva de roças e fauna aquática. [...] Em um ou dois séculos de conquista, entretanto, as sociedades complexas e suas populaçóes desapareceram completamente da maior parte das várzeas, e nada, mesmo remotamente parecido, pode ser encontrado nas atuais sociedades indígenas da Amazônia (ROOSEVELT, 1992, p. 71).

O sistema de cacicados, portanto, é a descrição de sociedades complexas nas quais estão presentes hierarquias sociais muitas vezes descritas como protoestados. Para Michael Heckenberger (2002, p. 100), os ancestrais dos atuais Aruak teriam sido os primeiros a estabelecerem sociedades com sistemas de cacicados. Localizados no epicentro desse sistema, os Aruak também formavam uma vasta rede comercial. Como afirma France-Marie Remard-Casevitz (2002, 
p. 136), no contexto pré-colombiano, os Aruak do sul da Amazônia visitavam regularmente Cusco para comerciar e participar das celebraçôes dos Incas. Os Campa (Ashaninka, Matsiguenga, Nomatsiguenga e Yanesha) controlavam as regióes produtoras de sal, um importante produto redistribuído entre muitos povos do Vale Amazônico. Com o sal vermelho extraído das montanhas, eles fabricavam um bolo que utilizavam como moeda de troca no comércio. O comércio do sal permitia estender as alianças políticas e ampliar a rede das alianças matrimoniais (REMARD-CASEVITZ, 2002, p. 130-134). Portanto,

Em 1492, a maior parte das sociedades Aruak provavelmente estava organizada em cacicados regionais, mas é também importante reconhecer que estas sociedades estavam integradas em economias políticas regionais maiores, incorporando sociedades com uma variedade de ideologias, incluindo sociedades mais igualitárias, "predatórias" e autônomas (HECKENBERGER, 2002, p. 112). ${ }^{2}$

De semelhante forma, Jonathan Hill (1996a, p. 159-160), ao trabalhar com a etnogênese dos povos Aruak na fronteira entre a Colômbia e o Brasil, observa que a Cordilheira Andina, o Alto Orinoco e a Guiana estariam ligados em uma rota comercial. Haveria um intenso comércio de produtos como curare, resinas, óleo de tartaruga, peixe moqueado, ouro, sal, arcos e flechas, cestas, poçôes, pigmentos, algodão e produtos à base de algodão, pérolas e conchas. As conchas, como fonte de calcário, seriam importantes para o preparo da coca na região andina e também serviam como moeda de troca. Fernando Santos-Granero (2002, p. 32), por sua vez, também vai afirmar que os grupos Aruak foram o centro de uma enorme rede entre diferentes grupos indígenas. Nesse sentido, os geoglifos do sul da Amazônia brasileira provavelmente são construçôes Aruak e testemunham um tempo de grande atividade humana na regiáo (SCHAAN et al., 2008). Virtanen (2016, p. 51) correlaciona esses geoglifos e o sistema de estradas que os interligavam à estrutura de caminhos de terra firme construídos ainda hoje pelos Apurinã. Wanderley (2013, p. 142), por sua vez, registra que os Apurinã estudados por ela relacionariam os geoglifos com os personagens de sua mitologia; o que seria prova dos usos e apropriaçôes desses espaços.

Como visto acima, os Apurinã pertencem à família linguística Aruak e estavam no centro do território dos Aruak. Os Aruak podem ser encontrados atualmente desde o Paraguai, o Peru, a Bolívia, o Brasil, a Colômbia, a Guiana, a Venezuela até as Antilhas, o que demonstra sua importância no contexto pré-colombiano. Além disso, os Apurinã também mantêm o costume andino e pré-andino de mascar folhas de coca (katsupary na língua apurinã), o que pode ser tomado como prova de sua ligação com essa região. Assim é, pois, passível de

\footnotetext{
${ }^{2}$ Tradução própria. No original: "In 1492, the majority of Arawakan societies probably were organized into regional chiefdoms, but it is also important recognize that these societies were integrated in larger regional political economies, incorporating societies with a variety of ideologies, including more egalitarian, 'predatory', and autonomous societies".
} 
seriedade a hipótese de que os Apurinã mantêm viva em sua cosmologia a noção de viverem em uma terra do meio. Virtanen (2016, p. 42, 56), por exemplo, vincula claramente o domínio Aruak do Purus com essa relação ancestral pré-andina. Portanto, mesmo com a falta de pesquisas arqueológicas, pode-se tomar como verídica a hipótese de que os ancestrais dos Apurinã estavam no centro de uma vasta rede comercial. Ou seja, estavam realmente numa terra do meio como suas histórias míticas afirmam. A conquista da América modificou essa rede comercial e situou os Apuriná numa nova fronteira capitaneada entre as coroas da Espanha e de Portugal. Por no mínimo dois séculos, os Apurinã parecem ter vivido sob essa nova conjuntura, acessando esporadicamente os produtos ocidentais através de suas antigas redes comerciais. Isso é o que podemos depreender das fontes dos primeiros contatos já no século XIX que sinalizavam a existência de ferramentas de ferro, como facas, machados e anzóis, o uso de sal e de poncho e a presença de cachorros entre os indígenas da regiáo do Rio Acre (CHANDLESS, 1866b, p. 122, 123, 120).

Sobre os Apurinã, fontes do final do século XIX afirmaram que algumas lideranças falavam português, o que indica uma situação de contato mais sistemática (SAMM, 1876, p. 132; 1880, p. 270, CHANDLESS, 1866a, mapa). Os missionários anglicanos que atuaram no Purus entre as décadas de 1870 e 1880 também pontuaram relatos nos quais se pode depreender claramente que os diferentes grupos indígenas mantinham contatos com as sociedades não-indígenas por ocasião da repartição definitiva da última fronteira entre os estados nacionais. Nesse sentido, em $1^{\circ}$ de maio de 1876, o missionário Clough escreveu uma longa carta para a South American Missionary Society (SAMS), com sede em Londres, doravante apenas Sociedade, que foi publicada em três partes na Revista Missionária da Sociedade (SAMM, 1876, p. 203-208; 234-238; 278-282). Na terceira parte, ele traz informaçóes históricas muito importantes. Ele diz que no dia 22 de março de 1876 uma lancha da armada brasileira engajada na exploração do rio desde maio de 1875 aportou no Teruã. O barco tinha descido o rio até Hyutanahá com o objetivo de despachar as correspondências do comandante Andreas, o líder da expedição que teria ficado em Areca, e adquirir provisôes. A lancha estava sob o comando de George Remick, primeiro maquinista. Com ele também iam Raymundo como segundo maquinista, Polycarpo e João como responsáveis pela caldeira e um jovem português de nome Joaquim que estava muito doente e fora deixado em uma localidade a meio caminho de Hyutanahã e Teruã. Remick era inglês e havia acompanhado Asrael Piper na exploração do Alto Purus a serviço do governo Boliviano em 1872. Ele teria ficado na região com os índios Catiana (Manchineri) perto de Areca até outubro de 1874 quando se juntou à expedição. $\mathrm{O}$ missionário Clough aproveitou o momento para conseguir informaçôes e as registrou na forma de uma entrevista.

Remick teria dito a Clough que não haviam encontrado nenhum posto avançado de peruanos ou bolivianos no Rio Purus. Somente no Beni os peruanos podiam ser encontrados. No entanto, entre os rios Iaco e Manoel Urbano, ele teria encontrado inúmeras moedas 
bolivianas e peruanas, das quais as peruanas seriam em maior número. Os índios as usavam como adorno para o nariz. Ele também diz ter encontrado machados norte-americanos e facas de açougueiro Shefflied (Shefflied butcher knives). Como não havia presença de bolivianos e peruanos, a conclusão lógica era que os próprios índios empreendiam viagens comerciais. Assim Remick teria dito que os índios do Rio Manoel Urbano estavam familiarizados com o Rio Ucayali e que em Areca, ele teria conversado com um homem que esteve em Sarayácu, Cuzco, Pachitea, Tambo e no Lago Titicaca (SAMM, 1876, p. 279).

Dessa forma, assim como afirmam os primeiros expedicionários e missionários, podemos tomar como evidente que os povos indígenas do Purus náo viviam completamente isolados daquilo que se passava nas fronteiras de seus territórios. Mais do que isso, alguns grupos empreendiam expediçôes para obterem ferramentas e demais objetos desejáveis, as quais distribuíam para outros grupos no Vale do Purus. Vejamos como Clough reproduz uma fala histórica de Remick que sintetiza essa situação.

Depois do Mr. Piper partir para baixo [descer o rio], eu permaneci cerca de dois anos entre essa tribo [Manchineri]. Por um par de meses, ninguém falaria comigo, e eu tive que me virar do melhor jeito que pude; mas quando descobriram que eu podia reparar machados melhor do que eles - eu tinha algumas ferramentas e barras de aço - eu cresci em sua consideração, e centenas de índios vieram de longa distância para me ver. [...] eles comerciam com Cuzco, obtêm sal de uma mina e sua tradição oral e língua me levam a considerá-los como verdadeiros descendentes dos Incas. [...] Eles afirmaram que migraram para este rio para escapar da dominaçâo dos espanhóis (SAMM, 1876, p. 282). ${ }^{3}$

Como podemos ver, Remick estabeleceu sua fama entre os Manchineri pelos conhecimentos de metalurgia que possuía. A fala deixa entrever que os índios o procuravam para reparar seus equipamentos de ferro, mas mais do que isso, afirma também que os próprios índios detinham conhecimentos metalúrgicos e reparavam seu próprio material; quiçá não tâo bem quanto Remick por falta de matéria-prima, mas dominavam a técnica. Permanecendo cerca de dois anos entre os Manchineri, portanto muito mais do que qualquer "explorador", não temos por que duvidar das informaçóes que ele obteve. Linguisticamente, o povo Manchineri é o grupo Aruak mais próximo dos Apurinã e, portanto, muito do que pode ser dito sobre eles também pode ser aplicado aos Apurinã. Portanto, fica patente que os Manchineri mantinham ligaçôes comerciais com Cuzco, mas também é evidente que se

\footnotetext{
${ }^{3}$ Tradução própria. No original: “After Mr. Piper left for below, I remained nearly two years among this tribe [Catiana]. For a couple of months, no one would speak to me hardly, and I had to get along the best way I could; but when it was found I could repair axes better than themselves - I had some tools and steel bars - I grew into high favour, and hundreds of Indians came long distances to see me. [...] they trade with Cuzco, obtain salt from a mine and their oral traditions and language lead me to consider them of true Inca descent. [...] They assert they migrated to this river to escape the dominion of Spaniards [...]”.
} 
mantinham relaçôes comerciais, eles haviam se estabelecido no Purus justamente para fugir da dominação espanhola. Como uma regiáo de refúgio (BELTRÁN, 1979, p. 130), a terra do meio ainda era o lugar no qual podiam viver como sociedade independente. A fragmentação em pequenas aldeias parece assim ter inviabilizado ou dificultado a conquista de modo que o território apurinã permaneceu um território do meio por muito tempo. Esse também é o argumento de Remard-Casevitz (2002, p. 128-129) quando afirma que os espanhóis tiveram dificuldades de submeter os Aruak meridionais. Militarmente teria sido impossível impor um controle já que eles eram muito fragmentados politicamente. James Scott (2009, p. 22), para quem Pierre Clastres foi o principal teórico, também argumenta que a história das fronteiras dos Estados é a história dos povos que fogem e resistem ao Estado. $\mathrm{O}$ argumento de Scott é uma desconstrução do discurso civilizacional chinês e outras civilizaçôes acerca dos "bárbaros", dos "primitivos". Para ele, esses termos praticamente significariam não-governados, não-ainda-incorporados (SCOTT, 2009, p. 98-100). Dessa forma, ficar na terra do meio pode significar escapar dos grandes cacicados ou mesmo do controle estatal, tanto no período anterior pré-conquista quanto no período pós-conquista; significa escapar ao controle que advinha tanto do Amazonas quanto dos Andes.

Viver nessa terra do meio, não obstante, não significa viver isolado. Ela é uma área de transição como a narrativa apurinã bem registra e como as evidências indicaram. Os indígenas engajavam-se, tanto no período pré-hispânico quanto no período hispânico, em redes comerciais com o objetivo de obterem produtos e matéria-prima. Embora possamos conjecturar que os ancestrais dos Apurinã participavam dessas redes de comércio e das relaçôes interétnicas, não foi possível localizar provas definitivas. Apenas alguns indícios sugeririam nesse sentido. Portanto, no fim do século XIX, é difícil sustentar que as relações dos Apurinã chegavam aos contrafortes andinos. Mas, com certeza, eles participavam desse comércio e obtinham ferramenta ou manufatura através da mediação de outros povos como os próprios Manchineri. No entanto, se os Apurinã não comerciavam tão a montante, o mesmo não pode ser dito das relaçóes a jusante. Mantendo sua independência na terra do meio, os Apurinã ansiavam por ferramentas de ferro e manufaturas as quais utilizavam em sua própria lógica cultural e assim estabeleciam relaçôes comerciais com os não indígenas, karywa ou ïparãnyry na língua apurinã. O primeiro etnônimo é um empréstimo da Língua Geral Amazônica; o segundo provém da própria língua apurinã e poderia ser traduzido como "aqueles que chegam com a época das chuvas" (LINK, 2016, p. 59-60).

\section{A memória da terra do meio ou a realidade histórica vivida como mito}

Durante dois ou três séculos após a conquista da América, os Apurinã teriam permanecido nesse território do meio. Os séculos XVI e XVII provavelmente foram séculos de 
diminuição populacional provocada, sobretudo, por epidemias nos quais os cacicados se desfizeram e as redes comerciais e migratórias ancestrais foram diminuídas exponencialmente, mas a memória de viverem em uma terra do meio perdurava na memória coletiva. No século XVIII, provavelmente a densidade populacional atingiu certa estabilidade devido às pequenas aldeias que dificultavam a transmissão de enfermidades. Já durante o século XIX, mais especificamente na segunda parte do século XIX, Brasil, Bolívia e Peru disputaram literalmente o controle sobre a última fronteira que estava sendo incorporada através da exploração da borracha.

Com a exploração das "drogas do sertão", a região foi sendo ocupada pelos karywa já no século XVIII, mas foi em meados do século XIX que a presença dos ĩparänyry se intensificou e o território apurinã deixou de ser uma "terra do meio" para ser literalmente uma terra de fronteira. No entanto, essa situação duraria menos de uma década. Coincidindo com o período de atuação dos missionários anglicanos - década de 1870 -, a última expansão brasileira estenderia a fronteira para além do território apurinã, no Acre. No final da década de 1870, a fronteira - imperial e posteriormente republicana - não era mais a regiâo dos Apurinã, mas sim a região do atual Estado do Acre disputado com a Bolívia devido ao seu potencial de produçáo de borracha. Através de conflito armado e de diplomacia, o Brasil garantiu a posse do atual território do Acre com a celebração do Tratado de Petrópolis no dia 17 de novembro de 1903. No entanto, duas décadas antes de o Brasil ter garantida a sua última grande fronteira, o território dos Apurinã era mais uma vez um território do meio. Barcos iam e vinham de Manaus para o Acre e do Acre para Manaus. A região do Médio Purus, também produtora de borracha, entrou no eixo do comércio e da indústria internacional e os Apurinã se viram vivendo novamente entre mundos. Os próprios Apurinã foram se incorporando na empresa de exploração da borracha com o objetivo de adquirir bens industrializados, principalmente armas de fogo e ferramentas metálicas. Mas se os Apurinã tiraram vantagem da situação para conseguirem bens desejáveis, eles também estavam agora irreversivelmente amarrados ao novo sistema exploratório que instituía novas relaçôes sociais dentro de sua própria sociedade. Assim, os Apuriná viram seu território tradicional ser ocupado pelos ĩparänyry. As novas relaçôes trouxeram doenças, conflitos, muitas mortes e lentamente modificaram a forma como os Apurinã enxergavam a terra do meio. Se antes resolveram se estabelecer ali pela fartura, agora a terra era descrita como terra "morredoura", "terra de cupim" (SCHIEL, 2004, p. 93, 241).

Recapitulando, no início da exploraçáo da borracha, o povo Apurinã estava numa condição de fronteira, mas logo as pessoas que adentravam em seu território em busca da goma elástica estavam adentrando o território do Acre e mais além. Assim, os Apurinã estiveram em um curto espaço de tempo na condiçáo de viverem em uma terra de fronteira para voltarem logo em seguida a viverem em uma terra do meio, mas agora sob nova conjuntura. $\mathrm{Na}$ verdade, seu território pode ser melhor descrito como uma terra do meio. Geograficamente, 
há que se constatar que o Vale do Purus está localizado entre dois rios de igual importância, o Madeira e o Juruá. Historicamente, e em primeiro lugar, os ancestrais dos Apurinã viveram entre as sociedades complexas dos Andes e de seus contrafortes e os grandes cacicados da Amazônia, aqueles descritos pelos cronistas e evidenciados pela arqueologia ao longo dos rios Solimões, Negro e Amazonas. Em segundo lugar, a emergência dos impérios de Portugal e da Espanha remodelou a conjuntura histórica ao ocupar o lugar dos cacicados e dos Incas, mas ironicamente manteve os ancestrais dos atuais Apurinã vivendo na condição de terra do meio. No período de expansão e consolidação das fronteiras dos estados nacionais do Peru, da Bolívia e do Brasil, o território apurinã continuou situado na condição intermediária, mas agora redefinida entre o Estado do Acre e a cidade de Manaus. Portanto, essa dinâmica é estrutural e atualmente é melhor expressa entre as cidades de Rio Branco e Manaus. Nesse sentido, considerando seu território como estando no meio do mundo (ou como uma terra do meio, uma terra de passagem), a cosmovisão apurinã desvela uma estrutura de longa duração que pode ter sua origem na época pré-colombiana. Em todo caso, essa estrutura apresenta uma situação social vivida pelo povo Apurinã desde pelo menos o final da década de 1870, na qual se encontram vivendo no meio de dois importantes centros econômicos da regiāo: Manaus e Acre. Manaus como centro econômico que concentra a exploração econômica de toda a Amazônia Ocidental; e Acre como o centro de exploraçáo de matéria-prima. A partir daí, a vida dos Apurinã do Médio Purus girou entre esses dois centros; e muitos Apurinã podem ser encontrados vivendo ou transitando entre eles.

A título de exemplo, narro o caso de Otávio Avilino Chaves (Tukatxi). Nascido no Igarapé Txiburiâ, na atual terra indígena Guajarã. Conforme seu documento de identidade, ele teria nascido em 1925. Seu pai era José Avelino Chaves (Makawary, também conhecido como Doutor) e sua mãe Tereza Vicente. Seus avós paternos eram João Pequeno (Waya) e Maria Vicente (Xuwarua). E seus avós maternos eram Tuxaua Vicente (Mamurity) e Emília Manduca (Kimiu). Em torno dos 10 ou 11 anos de idade, foi para Manaus morar com sua irmã que era casada com um ĩparãnyry. Ali viveu vários anos tendo trabalhado como pedreiro e quebrando pedra. Em Manaus teria se envolvido com uma karywa e tido filhos. Depois de alguns anos decidiu regressar para o Purus e deixou sua mulher. Passou algum tempo trabalhando em Tawaruá, uma localidade abaixo de Lábrea. Seu trabalho era abrindo roçado (brocando na linguagem local), fazendo lenha para as embarcaçóes a vapor e cortando seringa. Diz ter feito isso em vários pontos do Purus, inclusive no Acre. Depois dos vinte e poucos anos, sua mãe Tereza Vicente (Makaye) o fez casar com Raimunda Franca da Silva, uma mestiça, e então ficou mais estável. Eles tiveram dois filhos, Abdias Franco da Silva Chaves (Kuyuty) e Denisa Franco da Silva Chaves (Anikäaru). Abdias e sua família residem atualmente na Terra Indígena Água Preta. Denisa reside em Rio Branco no Acre com sua família. Depois da morte de sua mulher, Otávio ainda passou um tempo em Manaus, mas regressou e reside atualmente com seu filho no Igarapé Água Preta. Para 
uma genealogia mais detalhada, inclusive de outras famílias, sugiro a consulta da tese de Juliana Schiel (2004, p. 394, 398).

Marco Antonio Lazarin, trabalhando com um grupo de Apurinã que desceu o $\mathrm{Rio} \mathrm{Pu}$ rus e se estabeleceu em Manacapuru, aponta para a simbologia que essa descida representa. Para ele, seria simbolicamente a travessia do mundo indígena para o mundo não indígena. A descida do rio é a continuação da subida dos ĩparânyry. Manacapuru era inclusive terra natal de Manoel Urbano, o primeiro desbravador da região. Assim, "ao descer o rio, o Apurinã separa-se da 'situação histórica' que o construiu como 'índio" (LAZARIN, 1981, p. 38). Os Apurinã migram em busca das vantagens da "civilizaçáo" e encontram uma estrutura social que lhes permitiria ascender a uma condição de "caboclo". Agora, mesmo enfrentando estereótipos e náo conseguindo escapar totalmente da sina de serem índios que esses estereótipos instituem, eles se considerariam "índios civilizados" (LAZARIN, 1981, p. 41-42).

Assim como na narrativa mítica, parece que os Apurinã de Manacapuru descritos por Lazarin viam o Purus como a terra do meio na qual as condiçóes de vida não eram táo boas quanto onde se encontravam. Descer o rio pode significar, assim, uma continuação da migração para Iputuxity. De semelhante forma, a prática dos Apurinã entregarem suas crianças para os ïparänyry, como fora registrado pelos missionários anglicanos, pode significar uma continuidade de ethos anterior ao contato (rito de passagem) com o qual eles mantinham relaçôes de parentesco com outras aldeias apurinã e outros povos indígenas (LINK, 2016, p. 138). Mas, também, no caso da entrega das crianças para os karywa, pode estar representando aqui um paralelo com as viagens míticas dos Apuriná; ou seja, ir com os karywa pode ser comparado a ir com os Utsamanery. A realidade histórica é vivida assim como mito (SAHLINS, 2008 [1981], p. 38).

Estar-se-ia aqui, portanto, frente a uma estrutura de longa duração. A transitoriedade apurinã ganhava, assim, cada vez mais incentivo e se estruturava como material e espiritual. No âmbito material, ela desvela um mundo no qual os Apurinã estavam inseridos, ora comerciando ora fugindo das frentes de ocupação. $\mathrm{Na}$ ordem espiritual, estruturou uma cosmologia/teologia de estarem vivendo na terra do meio, entre duas terras boas, de fartura, abundância e eternidade. A última expansão dos estados nacionais possibilitou o acesso mais facilitado aos bens desejados, mas também trouxe desestruturação, conflitos e doenças, o que se traduziu rapidamente em declínio populacional. Essa nova situação também ficou inscrita na memória coletiva, o que faz os Apurinã descreverem seu território como uma "terra de cupim". Se os Apuriná outrora resolveram ficar na terra do meio pela sua abundância e fartura, agora a veem como uma terra "morredoura" (SCHIEL, 2004, p. 93, 241), uma terra de muitas privaçóes e sofrimentos experienciada no contexto da ocupação recente de seu território pelos ĩparãnyry. Essa representação é, dessa forma, ao mesmo tempo material e espiritual. 


\section{Conclusão}

O objetivo do artigo foi procurar evidenciar a materialidade histórica presente na memória mítica do povo Apurinã. Dessa forma, foi levantada a hipótese de que a cosmovisão apurinã que situa esse povo como um "povo do meio" teria sua origem na imanência histórica e, como tal, sofreu mudanças na longa duração, transformando-se em transcendência teológica. Como foi evidenciado, a memória mítica estruturou uma realidade histórica que situa os Apurinã em uma "terra do meio" entre as duas terras sagradas Kairiku e Iputuxity. Assim, os Apurinã mantêm vivas na memória coletiva as migraçóes ancestrais Aruak que os situaram como senhores do Médio Purus. A fartura e a liberdade encontrada no Purus foram os atrativos que os fizeram sair de uma região onde havia muita gente; provavelmente os contrafortes andinos. No entanto, se as narrativas míticas ainda afirmam o Purus como uma terra de abundância e liberdade, o contexto do pós-contato também deixou suas marcas na narrativa mítica. Os conflitos, as mortes e principalmente as enfermidades advindas da chegada dos não indígenas fizeram os Apurinã descreverem a terra do meio também como uma terra morredoura. A realidade histórica foi assim reescrevendo o mito. E essa reescrita foi além, pois, enquanto as terras míticas viraram teologia, os Apurinã foram novamente situados numa terra do meio entre duas terras de fartura e abundância no plano imanente: Manaus, no Amazonas e Rio Branco, no Acre. E os Apurinã podiam novamente ser encontrados transitando entre dois mundos.

\section{Referências}

BELTRÁN, Gonzalo Aguirre. Regions of refuge. Oklahoma City: Society for Applied Anthropology, 1979.

BRANDÃO, Ana Paula; FACUNDES, Sidney da Silva. Estudos comparativos do léxico da fauna e flora Aruák. Bol. Mus. Para. Emílio Goeldi. Ciências Humanas, Belém, v. 2, n. 2, p. 109-131, mai-ago. 2007.

CARVAJAL, Gaspar. Descobrimentos do rio das Amazonas. São Paulo: Editora Nacional, 1941.

CHANDLESS, Willian. Ascent of the River Purûs. Journal of the Royal Geographical Society of London, v. 36, p. 86-118, 1866 a.

CHANDLESS, Willian. Notes on the River Aquiry, the principal affluent of the River Purûs. Journal of the Royal Geographical Society of London, v. 36, p. 119-128, 1866 b.

HECKENBERGER, Michael J Rethinking the Arawakan Diaspora: hierarchy, regionality, and the Amazonian formative. In: HILL, Jonathan D.; SANTOS-GRANERO, Fernando 
(orgs.). Comparative arawakan histories: rethinking language family and culture area in Amazônia. Illinois: University of Illinois, 2002. p. 99-122.

HILL, Jonathan D. Ethnogenesis in the Northwest Amazon: an emerging regional picture. HILL, Jonathan D. (ed.). History, power, and identity: ethnogenesis in the Americas, 14921992. Iowa City: University of Iowa Press, 1996a. p. 142-160.

HILL, Jonathan D. Shamanism, colonialism and de wild woman: Fertility cultism and historical dynamics in the Upper Rio Negro Region. In: HILL, Jonathan D.; SANTOSGRANERO, Fernando (orgs.). Comparative arawakan histories: rethinking language family and culture area in Amazônia. Illinois: University of Illinois, 2002. p. 223-247.

HILL, Jonathan D.; SANTOS-GRANERO, Fernando. Introduction. In: HILL, Jonathan D.; SANTOS-GRANERO, Fernando (orgs.). Comparative arawakan histories: rethinking language family and culture area in Amazônia. Illinois: University of Illinois, 2002. p. 1-22. LAZARIN, Marco Antônio. A descida do Rio Purus: uma experiência de contato interétnico. Dissertação (Mestrado em Antropologia) - Programa de Pós-Graduação em Antropologia Social, Universidade de Brasília, Brasília, 1981.

LÉVI-STRAUSS, Claude. O cru e o cozido. Mitológicas I. 2. ed. São Paulo: Cosac Naify, 2010 [1964].

LINK, Rogério Sávio. Vivendo entre mundos: o povo Apurinã e a última fronteira do Estado brasileiro nos séculos XIX e XX. Tese (Doutorado em História) - Programa de PósGraduação em História, Universidade Federal do Rio Grande do Sul, Porto Alegre, 2016.

PASSES, Alan. Both Omphalos and Margin: on how the Pa'ikwené (Palikur) see themselves to be at the center and the edge at the same time. In: HILL, Jonathan D.; SANTOSGRANERO, Fernando (orgs.). Comparative arawakan histories: rethinking language family and culture area in Amazônia. Illinois: University of Illinois, 2002. p. 171-195.

PORRO, Antônio. As crônicas do rio Amazonas: tradução, introdução e notas etno-históricas sobre as antigas populaçôes indígenas da Amazônia. Petrópolis/RJ: Vozes, 1993.

REMARD-CASEVITZ, France-Marie. Social forms and regressive history: from the Campa cluster to the Mojos and from the Mojos to the Landscaping Terrace-Builders of the Bolivian Savana. In: HILL, Jonathan D.; SANTOS-GRANERO, Fernando (orgs.). Comparative arawakan histories: rethinking language family and culture area in Amazônia. Illinois: University of Illinois, 2002. p. 123-146.

ROOSEVELT, Anna Curtenius. Arqueologia Amazônica. In: CARNEIRO DA CUNHA, Manuela (org.). História dos indios no Brasil. Sáo Paulo: Companhia das Letras, 1992. p. 53-86.

SAHLINS, Marshall [1987]. Ilhas de história. Rio de Janeiro: Zahar, 1997.

SAHLINS, Marshall [1981]. Metáforas históricas e realidades míticas: estrutura nos primórdios da história do reino das ilhas Sandwich. Rio de Janeiro: Zahar, 2008. 
SAMM (South American Missionary Magazine). Anos 1873-1890. Londres.

SANTOS-GRANERO, Fernando. The arawakan matrix: ethos, language, and history in native South America. In: HILL, Jonathan D.; SANTOS-GRANERO, Fernando (orgs.). Comparative arawakan histories: rethinking language family and culture area in Amazônia. Illinois: University of Illinois, 2002. p. 25-50.

SCHAAN, Denise Pahl; PÄRSSINEN, Martti; RANZI, Alceu. Arqueologia da Amazônia ocidental: os geoglifos do Acre. Belém: UFPA, 2008.

SCHIEL, Juliana. Tronco Velho: histórias apurinã. Tese (Doutorado em Ciências Sociais) - Programa de Pós-Graduaçáo em Ciências Sociais, Universidade Estadual de Campinas, Campinas, 2004.

SCOTT, James C. The art of not being governed. An anarchist history of upland Southeast Asia. London: Yale University Press, 2009.

VIRTANEN, Pirjo Kristiina. Redes terrestres na região do Rio Purus que conectam e desconectam os povos Aruak. In: MENDES DOS SANTOS, Gilton; APARICIO, Miguel (orgs.). Redes Arawa: ensaios de etnologia do Médio Purus. Manaus: EDUA, 2016. p. 4163.

WANDERLEY, Elaine. É pote de parente antigo! A relação de indígenas Apurinã da Terra Indígena Caititu com os sítios e objetos arqueológicos, Lábrea/AM. Dissertação (Mestrado em Antropologia) - Programa de Pós-Graduação em Antropologia, Universidade Federal do Pará, Belém, 2013.

WHITE, Hayden [1978]. Trópicos do discurso: ensaios sobre a crítica da cultura. 2. ed. São Paulo: Editora da Universidade de São Paulo, 2001. 